\title{
Writing the organisational crisis: embodied leadership engaged through the lens of a playscript
}

\author{
Christopher Michael Conroy (1) and Craig Batty \\ Faculty of Arts and Social Sciences, University of Technology Sydney, Sydney, Australia
}

\begin{abstract}
In a sea of endless stories of corporate ethical scandals, many of which are attributed to 'failed leadership', this article examines how creative writing research is being used as a way of inspiring - or suggesting - new forms of leadership behaviour. In the processual nature of being in our lives, if experience is valued as primary to consciousness as a way of active belonging, then it will be argued that creative writing here, scriptwriting specifically - is a powerful medium to examine organisational experiences. This research practice occurs through the lens of affect in embodied responses to such experience, as distinct from the singular, scientific mode of cognitive analysis that can cause us to habitually jump too quickly to conclusions about our experiences. By employing the affective methodology of creative practice research, which in this case forms the basis for a PhD currently in candidature, this article speculates how creative writing might disrupt habitual thinking through the elevation of emergent data from our physical senses. Creative writing can, we argue, provide a balance for science to work with art and craft, and in doing so encourage new thinking in the fields of organisational behaviour, relational leadership and creative practice research.
\end{abstract}

that writes, and on the bodies that read, listen or view' (Probyn 2010, 76). As Dallas Baker (2018) argues, through the performative act of reading a work of creative writing, not only does understanding accrue, an affective, embodied experience also occurs; knowledge is not merely contained in the text itself, it also occurs through an act of participation between author, reader/ viewer, character and action. It is with this stance that we approach this article, exploring how, in the context of the lead author's PhD currently in progress, creative practice research - here, creative writing - can be used as a method with which to contribute to the field of organisational leadership. Specifically, how might writing a playscript about authentic and ethical behaviour in the workplace encourage an understanding of the workplace that explores emergent themes beyond traditional conscious analysis of discur- sive social construction, to consider the direct embodied experience of organisational 
members who each have the capacity to affect through - and to be affected by - those experiences?

So, why creative writing and organisational leadership? In a time of endless stories of corporate ethical scandals, public sector corruption, unethical religious institutional responses to child sexual abuse crimes and ball tampering in international cricket many of which are attributed to 'failed leadership' (Ferris 2018) - creative writing is a useful vessel for mapping, plotting and giving voice to the protagonists, antagonists, mentors, gatekeepers and bystanders of these stories (see Berry and Batty 2016). As one example here in Australia, recent transcripts of hearings from the Royal Commission into Misconduct in the Banking, Superannuation and Financial Services Industry demonstrate the impact of financial institutional greed on the lives of innocent people and their loved ones. As Commissioner Kenneth Hayne detailed in the executive summary of his interim report:

Too often, the answer seems to be greed - the pursuit of short-term profit at the expense of basic standards of honesty. How else is charging continuing advice fees to the dead to be explained? (Commonwealth of Australia 2018a, Interim Report, xix)

Described by some victims and observers as 'sickening', humiliating, belittling to the point of depression (Lawrence 2018), we argue, therefore, that such exposure of unethical behaviour possesses an ability to affect our bodies.

When Commonwealth Bank of Australia (CBA) internal whistle-blower Jeff Morris exposed the actions of 'Dodgy Don', a CBA financial planner who allegedly forged signatures, overcharged fees and created unauthorised investment accounts for his customers without their permission, Morris contributed to setting in motion the 2018 commencement of the Royal Commission. It went like this:

Morris: I remember going to my first office Christmas party [in 2008]. It was barefoot bowls, and in the middle of it, the managers started yelling, 'Hey, listen up everyone! Don's done it again! He's got an 86-year-old woman to sign up for \$1.6 million and he's charging her 2 per cent up front $\$ 32,000$ !' This is for a boiler-plate financial plan produced in an hour. 'Where does he find these little old ladies?! Ring the bell!!!' (Hooten 2018)

Imagine us making $\$ 32,000$ for an hour's work, filling out a few 'off the shelf' forms with an unsuspecting 86-year-old. Imagine this is our job. A job supported by our manager, our company, our whole corporate structure. A job for which we will be celebrated professionally and given a bonus. Morris recalled feeling "like Alice in Wonderland' within weeks of starting at the CBA: 'It was this feeling of, "Am I the only one who thinks this whole thing is just wrong?"' (Hooten 2018). Experiences like those of Morris 'generate affective responses; responses that live on in our flesh, layered as new events unfold that remind the body how it feels to feel' (Pullen, Rhodes, and Thanem 2017, 106).

Transcripts of events such as this Royal Commission read like a playscript, with the posturing of interrogators circling their hapless banking executive prey in the witness box:

Mark Costello, counsel assisting the Royal Commission: You're aware of the fees-for-no-service issues that Commonwealth Bank [CBA] has had?

Executive A of Colonial First State, owned by CBA: Yes, I am. 
Costello: And you know that Commonwealth Bank group entities have charged more fees for no service than any other financial services entity in the country; do you know that?

Executive A: I do know that.

Costello: It would be the gold medallist if ASIC [the Australian Securities and Investments Commission] was handing out medals for fees for no service, wouldn't it?

Executive A: Yes.

(Commonwealth of Australia, 2018b, 1258)

The idea that it requires a Royal Commission to get to the truth of unethical conduct in all organisations would clearly be excessively expensive and implausible. But it does raise the prospect of identifying innovative ways for organisations to 'get to the truth' and for people within organisations to stand back and reflect on their own actions as perpetrators, bystanders, victims and whistle-blowers on the organisational stage. Creative writing, in this case a playscript that aims to offer an affective experience, we posit has the potential to assist. Creative writing as a mode of research that might inspire and support new forms of authentic leadership behaviour - in theory and in practice.

The purpose of this paper, then, is to consider the potential of creative writing to intervene and make a new contribution to organisational leadership. Drawing on Conroy's development of the script Work. Life. Balance. from a PhD that draws on organisational leadership studies to produce 'a creative-critical driving force that results in the creative work' (Batty et al. 2017, 15) we examine how theories and ideas from those who study workplace leadership can manifest in plots, characters and other narrative devices that explore the same themes. Baker (2018) highlights the value of playwriting to trigger emotional responses in a reader, and Batty $(2018,10)$ argues that fictional narratives 'enable ideas to be shown and felt, not merely told'. Drawing on material thinking and process philosophy, we explore how emotion and affect within creative writing (as method) can contribute ideas about the world we live in, and - ultimately - initiate change.

\section{Engaging with leadership through creative practice}

Organisational leadership theorists Steven Taylor and Hans Hansen (2005) usefully identify the tension between instrumental/intellectual work and artistic/aesthetic work, claiming: 'Aesthetic forms of expression are like experiments that allow us to reconsider and challenge dominant categories and classifications ... [they] not only transform organisations, but the lenses we use to view them' (Taylor and Hansen 2005, 1216). Taylor and Hansen employ a two-by-two quadrant management theorising method for detailing the field of organisation aesthetics (see Table 1, below; Taylor and Hansen 2005, 1217).

Conroy's PhD is situated in the relatively under-researched artistic-aesthetic quadrant, where artistic forms such as a playscript can be employed to present day-to-day experiences; in this case, that of organisations. Placing creative writing as a method within this quadrant corresponds to the work of Sophie Hope, namely the purple section of her Colour Wheel of Practice Research, 'Research through and for (as) practice' (Hope 2016); a model she developed from examining how practice features (as method or methodology) within a series of AHRC-funded (UK) research projects. In this sense, the playscript being developed is simultaneously the object of the study because of its content (set in an 
Table 1. Categories of organisational aesthetics research (Taylor and Hansen 2005).

\begin{tabular}{|c|c|c|c|}
\hline \multicolumn{4}{|c|}{ CONTENT } \\
\hline METHOD & Intellectual & $\begin{array}{l}\text { Instrumental } \\
\text { Artistic forms as metaphors for } \\
\text { organisations } \\
\text { - Lessons for management from arts } \\
\text { - } \text { orgumentsfor theimportance of } \\
\text { Using aesthetics to deepen our } \\
\text { understanding of traditional } \\
\text { organisational topics }\end{array}$ & $\begin{array}{l}\text { Aesthetic } \\
\text { - Industries and products fundamentally } \\
\text { aesthetic in nature } \\
\text { - } \text { Aesthetic forms in organisations } \\
\text { - The direct sensory experience of day-to-day } \\
\text { reality in organisations }\end{array}$ \\
\hline & Artistic & $\begin{array}{l}\text { Artistic forms used to work withindividual } \\
\text { issues } \\
\text { - Artistic forms used to work with } \\
\text { organisational issues } \\
\text { - Aesthetic forms used to illustrate/present } \\
\text { intellectual arguments }\end{array}$ & $\begin{array}{l}\text { Artistic forms used to present the direct } \\
\text { sensory day-to-day experience in } \\
\text { organisations }\end{array}$ \\
\hline
\end{tabular}

organisation), and the method of the study because of its creative writing form. The playscript is also the result of the research process, because embedded in the creative practice (the act of writing) a research process is emerging due to an engagement with the very practice (of writing) itself (Hope 2016, 83).

In her book Leadership Can Be Taught, Sharon Parks argues that art, artist and artistry should be given a more prominent place within the lexicon of leadership theory and practice:

Artists work within a set of relationships that they cannot fully control ... the artist works in a profoundly interdependent relationship with the medium - paint, stone, clay, a musical instrument, an orchestra, a tennis court, a slalom run, or food ... A potter, for example, must learn that clay has its own life, its own potential and limits, its own integrity. The potter develops a relationship with clay, spending time with it, learning to know its properties, how it will interact with water, discovering that if you work it too hard, it will collapse, and if you work with it, it will teach you its strength, your limits, and the possibilities of co-creation. $(2005,211)$

Parks' work is based on the case-in-point pedagogy of Harvard Business School Professor Ron Heifetz (Heifetz 1994), who believes that possibilities of co-creation exist between a single actor 'leader' and his/her followers. Ironically, the relevance of Parks and Heifetz to this article is not directly aligned to their perspectives on leadership, but rather, to the here-and-now, story-based sense-making that they offer through case-in-point pedagogy. Unlike the single-actor leader perspective of Parks, the leadership focus of our paper seeks to build upon leadership emerging from relationships (Balkundi and Kilduff 2005; Cunliffe 2009; Cunliffe and Eriksen 2011; Denis, Langley, and Sergi 2012; Hogg 2001; UhlBien 2006) and the radical reconceptualisation of leadership by Wood, Salovaara, and Marti (2018), Wood (2005) and Dibben et al. (2017) in terms of viewing 'leadership' as a process of becoming rather than an event or thing performed by an individual actor an emergent co-creation that occurs within the gap of the managerial leader-fol- lower dichotomy (Wood 2005).

Dibben et al. (2017) examine leadership through the lens of process metaphysics, where leadership is experienced subjectively within us as an internally complex occasion of experience. In contrast to a Kantian view, where 'the world emerges from the subject', Dibben et al. follow a Whiteheadian ([1929] 1978) view that 'the subject emerges from the 
world' as an organism belonging to a natural form of being that is a potential for every 'becoming' (2017, 171-172). Griffin (2008) follows Whitehead's 'serially ordered occasions of experience' by claiming that 'experience is always active not passive': 'it is not what happens to us that counts' (external relation), 'but rather what we make of what happens to us' (internal relation) (Griffin 2008 cited in Dibben et al. 2017, 172). In processoriented thought, then, experience is primary to consciousness: we must experi- ence something first before we can become conscious of it.

This process-oriented perspective of leadership thus creates potential for new knowledge to emerge about leadership through the 'ordinary affects' (Gherardi 2017) of organisational members' interactions, that 'moves leadership beyond a focus on simply getting alignment (and productivity) ... to a consideration of how leadership arises through the interactions and negotiation of social order among organisational members' (Uhl-Bien 2006,672 ). To examine such leadership dynamics as interactions and social order lends itself well, we argue, to a creative writing approach.

Writing about creative writing research and the development of innovative methodologies, such as the one we are proposing here, Sempert et al. argue that the responsive and reflexive nature of writing in the context of knowledge creation (i.e. a $\mathrm{PhD}$ ) results in a methodology; i.e. it is 'a way of working that emerges from the incubation of and reflection on a project/practice' (Sempert et al. 2017, 206). The authors argue that 'in creative writing research, both knowledge and text can be innovated through open-minded and reflexive research incubation' (Sempert et al. 2017, 207), and so the experimental, 'being willing to not know' (Taylor 2018,4) aspect of creative practice research is processual in nature.

Similarly, Batty (2016), Wood, Salovaara, and Marti (2018), Davis (2013), Taylor (2002, 2008) and Heathcote (1983) each argue for the capacity of creative writing - in the form of novels, scripts, poems and more - to evoke or render sensory experiences in an embodied, subjective, lived human experience. If, as Dibben et al. (2017), Griffin (2008) and Whitehead ([1929] 1978) assert, humans move to meet experience - what we make of what happens to us, as distinct from what simply happens to us - and if creative writing has the capacity to create that experience, then to examine the experience of organisational leadership through the lens of creative writing would appear to have significant potential. If, like art, leadership is experienced by the processes of its creation, then opportunities exist for incremental change to occur through the shifting tides of leadership. Put simply, might organisational actors paying attention to subtle 'ordinary affects' lead to more authentic, ethical leadership outcomes that can benefit organisations and the wider, human community (Gherardi 2017)? And if so, can creative writing help us achieve this?

\section{Creative writing, process philosophy and relational leadership: a playscript}

Scholars such as Wood (2005); Dibben et al. (2017); and Wood, Salovaara, and Marti (2018), who advocate through process philosophy that experience is primary to consciousness, adopt a focus on relations recently advanced by contemporary leadership and organisational scholars such as Balkundi and Kilduff (2005), Uhl-Bien (2006), Cunliffe (2009), Ladkin (2010), Denis, Langley, and Sergi (2012), Wood and Dibben (2015), Fotaki, Kenny, and Vachhani (2017) and Rhodes (2018). However, the focus of many contemporary scholars is more directly targeted to social construction dynamics, which includes 
'framing' - everyday talk and interaction where subordinates can meet a leader's attempts to frame a situation (accept or reject) - and where talk is coded in order to assert control, acquiesce, request control or neutralise control (Fairhurst 2004). Challenging this approach, Dibben et al. (2017) argue that traditional scholars focus on discursively based social construction but conceive leadership in terms of external relations between distinct and self-contained leaders and followers, an inter-subjective performance constructed through talk and text that helps us to create leadership through language and discourse (Collinson 2014; Fairhurst and Uhl-Bien 2012). In other words, discursive construction comes from conscious analysis, not from direct contact with experience. Consequently, framing creates an 'intellectual strait jacket' by mistaking the framing of leadership for leadership itself (Dibben et al. 2017, 178), thereby limiting the ability for change to occur.

To concretise this point, organisational change management theory operates in four basic steps: (1) a frozen-solid present state, or status quo, that for change to occur (2) needs to be unfrozen, prior to (3) an interim period of disruption and movement until the desired new state is reached, and then (4) a refreezing must occur to establish and embed the new status quo (Kotter 1996; Lewin 1951). Contrary to this view, in process philosophy, is that our lives are not a case of: things first are, then they change, then they are stable again. Rather, life is a processual series of dynamic acts of experience, and 'creative novelty', in terms of what is made of such experiences, is the very essence of the universe (Whitehead [1929] 1978). By resisting the intellectual strait jacket and not mistaking the framing of leadership for leadership itself, process philosophy closes the binary gap that underpins management as a social science of quality-quantity, man-nature, mindmatter, leader-follower (Dibben et al. 2017), in the context of capital-labour, employeremployee, management-staff, employers-unions. In short, between the power relations of 'them-and-us' lies organisational life.

A direct focus on the 'them-and-us' binary was central to a previous creative writing project undertaken by Conroy in the completion of his Executive Master of Arts (The University of Melbourne), in which he produced an original play titled The Myth of Themanus 21st Century Leadership in Action (Conroy 2015). This theatre script focused on toxic 'themand-us' organisational tensions, where Themanus, an ambitious new manager of production at Olive Groove, a fictional olive producer and wholesaler, finds his management role more difficult than expected. Not only are his superiors demanding and his management peers less than collegiate, he also has his plans derailed by a lowly subordinate, Mischievous. Despite having little formal organisational power or authority, Mischievous is able to employ his significant informal authority as a staff opinion leader to reject and undermine the control of Themanus, primarily through an absenteeism scam devised by Mischievous to increase the wages of staff via an overtime roster to cover for said sick, absent staff. When viewed through the lens of discursive social construction coming from conscious analysis, the actions of Mischievous that cause manager/leader Themanus to introduce a strict new absenteeism policy to block staff from accessing extra pay raises the question: who is leading whom? The question is validated in Mischievous' response to the overtime ban (Conroy 2015, 29-31):

Mischievous [calculatingly, as if hatching a new plan]: Themanus can run but he can't hide.

Titus: What d'ya mean Mischievous? What are ya thinking? 
Mischievous [assuredly]: Well, we can still take our sickies, can't we?

Titus: Yeah, but then we won't be able to work overtime so we'll be losing money.

Mischievous: We won't be the only ones losing money.

Titus: Why?

Mischievous: Think about it. If we all still take our sickies, and there is no-one coming in to backfill, there will be nobody to do the work.

Titus: So, who will do the work?

Mischievous: Only the staff who turn up.

Titus: But they're gunna get smashed if a number of people are off sick every day and they are not replaced with overtime! We're gunna have a huge production back-log!

Mischievous [calmly]: Exactly. And that backlog will build on itself every day ...

Curious: I don't understand what you're trying to achieve, Mischievous? We would be setting ourselves up to get slaughtered.

Mischievous: We're not the only ones who will get slaughtered. Can you imagine what Themanus' masters will do if he doesn't meet his precious performance targets? [pause] He'll get his backside kicked from here to kingdom come by Hoadley and the rest of executive.

Curious: Yes, but I still don't see the point in creating stress and ...

Mischievous [raising his voice to interrupt Curious]: The point is that our strategy will force Themanus to back-off. He'll have no choice but to allow us to work overtime on our RDOs, whether we've been off-sick or not. He will just have to get all hands-on-deck to clear the backlog and keep production moving.

Titus [becoming excited as he exits towards stage left]: We might even get more overtime out of it if we can create a big enough backlog!

When viewed through the traditional lens, this excerpt provides an example of social construction, with the designated 'leader' (Themanus) trying to exert control over the designated 'follower' (Mischievous) as an inter-subjective performance that conceives of leadership in terms of external relations between distinct and self-contained leaders and followers. If, instead, we investigate leadership through the alternative lens of a dynamic, ongoing, intra-subjective process of embodied experience - in the midst of things and (immanent) relations - the scenes, characters and plotlines can be viewed beyond external relations (i.e. what happens to us) to internal relations (i.e. what we make of what happens to us). In other words, our human capacity to affect and be affected. The focus of Conroy's PhD is whether the elevation of emergent data from our physical senses via creative practice can contribute to an investigation of leadership as an intrasubjective process that might disrupt the more traditional habitual scientific cycle (Ladkin and Taylor 2010), with the potential for assisting people in 'coming to their senses' (Springborg 2010, 243), including those with formal organisational leadership responsibilities.

Conroy's PhD playscript in development, Work. Life. Balance., charts the organisational action in a fictional Australian Government department, Federal Immigration and Border Security (FIBS). Using a maritime theme both as a metaphor for the processual, 
uncontrollable forces of nature and the context of border control surveillance set against the backdrop of a Government asylum seeker immigration policy, the plot centres around the power-abusing exploits of Waterside Control Director, Gino Genoa, and his purchase of a sports cruiser boat using taxpayer funds. The opening of the playscript aims to set a scene of control and surveillance, of codes of conduct, using images of seas, both raging and calm, and the human experiences contained within them. It begins like this:

\begin{abstract}
Spotlight shines on two empty stools at centre stage. The narrators, two uniformed staff, supervisors DEE and TAYLOR from Goods Arrivals Port Security (GAPS), walk onto the stage and sit quietly on the two stools, staring silently into the audience. Behind them is a wall of security screens monitoring activity on shipping wharves around the country. A musical piece, Walk on the Water, begins playing while on a large screen behind them, to the right, scrolling images appear: a rolling sea; waves crashing into the base of rocky, impenetrable escarpments; surfers cruising on an orderly set; spiritual images of a Christ-like figure walking on water; handcarved timber canoes; tall ships at full sail; black-and-white images of migrant ships (Greeks, Italians, 'ten pound Poms'); cruise liners squeezing under Sydney Harbour Bridge; winged keels; luxurious sports cruisers; leaky wooden boats; heavily laden container ships; 'high-rise' container stacks on wharves; a single red tanker floating on the horizon between sea and sky; stormy, threatening seas ...
\end{abstract}

The play is a deliberate attempt to evoke, or render, the lived (organisational/leadership) experience of Gino and his colleagues, including the characters of leaders, subordinates, coconspirators, bystanders and whistleblowers. The maritime theme both dramatises and thematises the workplace in relation to the human victims of FIBS' policies, namely its corporate HR policy and Operation Borders Downunder policy (i.e. asylum seekers). In the working draft, plotlines juxtapose the embodied lived experience of a variety of characters, creating experiences that generate affective responses; responses that live on in our flesh.

For example, Victor Nguyen and Morris Foster, who are placed on a redeployment list following the abolition of their Waterside Control positions by Gino, to make space in his budget so he can purchase the sports cruiser, become victims of HR staffing redeployment policies efficiently enforced by HR Manager Rhonda 'Radar' Radari. Pregnant Ellie Cunliffe is denied the opportunity to work part-time following the birth of her baby. Intelligence analyst Fatima Awse Abdullah is deviously distracted by Waterside Control manager Will Cruise so he can access her computer to input 'anonymous' information to justify operations in the sports cruiser only for Fatima to later be left, abandoned, with her integrity questioned, after a routine IT audit also locates inappropriate material on her computer. Finance manager Hope Adler, who has a 'gut feeling' about wrongdoing in FIBS, shares her frustrations with cargo manager Lester Whitehead, a former marine unit operative who witnessed, first-hand, the broader experience of asylum seekers intercepted by FIBS trying to enter Australia on suspected illegal entry vessels against Operation Borders Downunder policy.

Unlike other plays that chronicle the plight of asylum seekers via testimonial or verbatim theatre (Cox 2013), which seek to guide the audience to view the asylum seeker issue through a particular representational lens, Work. Life. Balance. aims to adopt a less political position and explore the less obvious, unexceptional happenings of ordinary affects in organisational life (Gherardi 2017). This is in order to 'slow the quick jump to representational thinking and evaluative critique long enough to find ways of 
approaching the complex and uncertain objects that fascinate because they literally hit us or exert a pull on us' (Stewart 2007, 7). In its textual form (at this stage), the creative practice research project is examining whether a fuller, more balanced and complete understanding of organisational life might be possible through the focus of our attention on affect, aesthetics and atmosphere attunement. We maintain that as well as woven into dialogue, this can occur via stage and actor directions given in parentheses, and in dramaturgical notes regarding proposed images appearing on large screens above the stage that highlight a character's nervousness, bewilderment, joy, passion, sadness, shock, dismay, love, anger, etc. These strategies acknowledge quite explicitly the presence in organisational life of the body, a body that knows through the senses and a body whose capacity to be affected, and to affect, is central to a relational epistemology where becoming is privileged with respect to being (Gherardi 2017, 355); that is, the ongoing processual responses to affects (internal relation, or what we make of what happens to us, post-affect).

Employing a more traditional lens directed at leadership development, Cunliffe argues for critical reflexivity, combined with moral activity and a relational epistemology, to understand and address pressures associated with ethical behaviour in organisations:

This way of thinking is important, recent corporate scandals have raised questions about the nature of ethical action and the pressures that leaders and managers face when trying to act in morally responsible ways. Critical-reflexivity offers a way of surfacing these pressures. $(2009,98)$

And so how does this intersect with, if not come to be usurped by, creative writing? As Sempert et al. (2017) observe in relation to research-led practice in the specific form of the lyric essay: 'A surprise, a flinch, a lifted brow; a nonsensical yet affectively vital effect. What occurs as a result of the movement between forces is more important than resolving the tension, or arriving at fixed knowledge' (Sempert et al. 2017, 208). This is what Work. Life. Balance. attempts to evoke through a close connection with relational leadership theory, which considers how relationships look, feel and appeal to one's conscious and unconscious aesthetic sensibilities (Uhl-Bien 2006). In a similar vein, Taylor and Hansen identify the tension between instrumental/intellectual work and artistic/aesthetic work, and claim: 'Aesthetic forms of expression are like experiments that allow us to reconsider and challenge dominant categories and classifications ... [they] not only transform organisations, but the lenses we use to view them' (Taylor and Hansen 2005).

Cunliffe asserts that she is 'advocating a relational, reflexive and situated approach in which self is always in-relation to, and ethically-responsible for, others' (Cunliffe 2009, 95). Following her belief that 'The basic practical-moral problem in life is not what to do, but what kind of person to be' (Shotter and Cunliffe 2002, 20), Cunliffe employs the Philosopher Leader as a metaphor for 'examining the interrelatedness of the emergent relational, ethical and reflexive nature of this approach' (Cunliffe 2009, 95). In so doing, she pulls together the three threads of relationality, moral activity and reflexivity, which can be discussed separately, but are 'inevitably and irrevocably entwined' as follows:

(1) ethical and moral actions are (2) embedded in relational understanding and (3) enacted through self- and critical-reflexivity. (Cunliffe 2009, 94) 
Potential exists here, in Conroy's PhD, to extend Cunliffe's metaphor by entwining the thread of critical reflexivity with the thread of creative practice. In this way, we argue that through characters and plotlines, the examination of this organisational phenomenon can be broadened to question fundamental assumptions about leadership, such as degrees of balance between brazen self-interest, vulnerability, service, fear, care for others and forces upon us, based on the premise that authentic leadership does not reside solely on one side of the dominant social science leader-follower dichotomy, nor is it limited to distinct and self-contained individuals; rather, it is more relational in nature and experienced through our bodies - bodies that have the capacity to affect and be affected - in an intra-connected dynamic collective assemblage, more associated milieu of becoming than a singular being.

If critical reflexivity means 'examining and unsettling our assumptions, actions and their impacts' (Cunliffe 2009, 94), then perhaps one way of creating such subtle, unsettling disturbances is through the use of creative writing as a form of what is called the 'minor gesture' (Deleuze and Guattari 1994; Manning 2016), used in the deterritorialisation of ideas/concepts/nature. Via 'a way of working that emerges from the incubation of and reflection on a project/practice' (Sempert et al. 2017, 206), not only in the case of this playscript but also in the creative writing PhD more broadly, might a response be possible to the question posed by Lather and St Pierre: "how do we think a "research problem" in the imbrication of an agentic assemblage of diverse elements that are constantly intra-acting, never stable, never the same?' (Lather and St Pierre (2013), cited in Gherardi 2017, 354, our emphasis).

By creating 'layers of complexity that mirror [the] subject matter' (Williams 2013), the richness of Conroy's playscript intends to surface emotion, which can be impactful to what we make of our experience (i.e. internal relation). According to Stroud, creative approaches to research such as this hold the power 'to move individuals to thought, reflection, action, and belief ... [and to] enable ideas to be shown and felt, not merely told' (Stroud 2008, 19). To operate in the here and now, using the situational present of making to reflect who we are and what the world means to us (Batty, 2016), might this type of work encourage organisational actors to reframe their objectives from developing authentic leaders to authentically developing leadership $($ Conroy 2015, 8)?

\section{Conclusion}

According to Lee et al., in their discussion regarding the writing of a screenplay for a creative practice $\mathrm{PhD}$, 'the nexus of the creative and the exegetical work is not whether one speaks to an aesthetic quality, industry or artistic satisfaction or one speaks to the academy, but how they might co-exist and inform one another' (Lee et al. 2015, 93). In the case of Conroy's PhD in progress, this is emerging in the form of an experimental 'way of working that emerges from the incubation of and reflection on a project/practice' (Sempert et al. 2017, 206); a 'not knowing' approach to writing, trying as a practitioner to generate affective responses, maintaining Conroy's focus on ordinary affects as they relate to characters who are in a constant state of becoming. Reflection on such affects in the redrafting of the work has resulted in practitioner observations regarding the behaviour of minor characters, some of whom are bystander witnesses to cruel or unethical behaviour, 
but who appear to turn a blind eye, keep their heads down or remain numb to behaviours that do not directly affect them. This has resulted in the emergence of unexpected themes in the playscript, which itself also appears to be in a constant state of becoming as characters 'talk' to their creator.

As Sempert et al. have observed, appropriating Kitchen (2011, 120):

The rhythm between thinking and making - like jazz riffs - is a co-created circularity, requiring a conduit of relationality ... [it] requires the reader to lean in and participate. And like a quality of connective tissue, the form is porous; it seeps beyond itself. $(2017,208)$

Drawing on insights such as those by Dibben et al. (2017), Wood, Salovaara, and Marti (2018), Wood (2005), Manning (2016), Deleuze and Guattari (1994), Mintzberg (2005), Parks (2005) and Batty et al. (2017), Conroy's PhD is using creative writing research in an attempt to assist in the quest for authentic, ethical organisational leadership, resulting in a playscript that 'thinks' - not just for the PhD, but potentially outside of the PhD, in the 'real world' of organisational leadership.

While it is true that such an approach could equally be accused of the same 'intellectual strait jacket' framing that Mark Dibben et al. question, the potential for researchled creative practice to evoke and render intra-subjective experiences for people engaging with it in the momentary here-and-now present, might enable the emergence of 'sites of dissonance, staging disturbances that open [and reorient] experience to new modes of expression' (Manning 2016, 2). As Taylor and Hansen argue:

The use of artistic forms to look at aesthetic issues offers a medium that can capture and communicate the felt experience, the affect, and something of the tacit knowledge of the day-today, moment-to-moment reality of organisations. Not just the cleaned-up, instrumental concerns of 'the business', but the messy, unordered side as well ... a holistic way to get at the whole of the experience, something that the intellectualization and abstraction of traditional organisational research often seems to miss. $(2005,1224)$

In twenty-first century organisations, not only the banking, superannuation and financial services industry, or religious institutions subject to the 2017 Royal Commission into Institutional Responses to Child Sexual Abuse, but in all organisations, the need to find methods of enquiry that move beyond the dualistic binary ways of perceiving the world has rarely been more essential. In Conroy's fictional world of FIBS, an emergent exploration of the embodied life experiences of characters seeks to inspire different perspectives and new knowledge to emerge. Latour (2004) maintains that 'to have a body is to learn to be affected, meaning effectuated, moved, put into motion by other entities, humans or non-humans. If you are not engaged in this learning you become insensitive, dumb, you "drop dead"' (Latour 2004, 205). When CBA whistleblower Jeff Morris questions if he is 'the only one who thinks this whole thing is just wrong', perhaps he can take comfort in the knowledge that his engagement in the learning to which Latour refers has served him well (Morris 2018) - at least in terms of daring to care (Adler 2012) through his embodied sense of common humanity.

\section{Disclosure statement}

No potential conflict of interest was reported by the authors. 


\section{Notes on contributors}

Professor Craig Batty is Head of Creative Writing at the University of Technology Sydney. He is the author, co-author and editor of books including Writing for the Screen: Creative and Critical Approaches (2nd ed.) (2019), Screen Production Research: Creative Practice as a Mode of Enquiry (2018) and Screenwriters and Screenwriting: Putting Practice into Context (2014). Craig is also a screenwriter and script consultant, with experiences in short film, feature film, television and online drama.

Christopher Michael Conroy is a current PhD candidate at the University of Technology Sydney. He is the author of a play The Myth of Themanus - 21st Century Leadership in Action (2015). Following 25 years in public sector management practice across a variety of industry environments, he has pursued academic research presenting 'Leadership' papers at organisational leadership-related conferences in Italy (EGOS 2016) and the UK (ISLC 2018). Since 2016, Chris has been teaching a range of university undergraduate and postgraduate management subjects with a view to fostering business student awareness regarding the nascent value of arts for business.

\section{ORCID}

Christopher Michael Conroy (1) http://orcid.org/0000-0003-2732-9220

Craig Batty (1) http://orcid.org/0000-0002-8542-4763

\section{References}

Adler, N. J. 2012. "Leadership Artistry: Daring to Care." Organizational Aesthetics 1 (1): 5-10.

Baker, D. J. 2018. "Play Scripts as Knowledge Objects.” New Writing 15 (2): 175-179.

Balkundi, P., and M. Kilduff. 2005. "The Ties That Lead: A Social Network Approach to Leadership." The Leadership Quarterly 16 (6): 941-961.

Batty, C. (Writer). 2018. "A Vacuous Screenplay in Search of Rigour." TEXT: Journal of Writing and Writing Courses, Special issue 48: 1-18.

Batty, C., K. Beaton, S. Sculley, and S. Taylor. 2017. "The Screenwriting PhD: Creative Practice, Critical Theory and Contributing to Knowledge." TEXT: Journal of Writing and Writing Courses, Special issue 40: $1-17$.

Berry, M., and C. Batty. 2016. "The Stories of Supervision: Creative Writing in a Critical Space." New Writing: The International Journal for the Practice and Theory of Creative Writing 13 (2): 247260.

Collinson, D. 2014. “Dichotomies, Dialectics and Dilemmas: New Directions for Critical Leadership Studies?" Leadership 10 (1): 36-55.

Commonwealth of Australia. 2018a. "Royal Commission into Misconduct in the Banking, Superannuation and Financial Services Industry." Interim Report, Volume 1. Accessed January 23, 2019. https://financialservices.royalcommission.gov.au/Pages/interim-report.aspx.

Commonwealth of Australia. 2018b. "Royal Commission into Misconduct in the Banking, Superannuation and Financial Services Industry." Transcript of Proceedings 18 April 2018. Accessed October 21, 2018. https://financialservices.royalcommission.gov.au/public-hearings/ Pages/transcripts.aspx.

Conroy, C. M. 2015. The Myth of Themanus: 21st Century Leadership in Action. Melbourne: Paragon.

Cox, E., ed. 2013. Staging Asylum: Contemporary Australian Plays About Refugees. Strawberry Hills, NSW: Currency Press.

Cunliffe, A. L. 2009. "The Philosopher Leader: On Relationalism, Ethics and Reflexivity - A Critical Perspective to Teaching Leadership.” Management Learning 40 (1): 87-101.

Cunliffe, A. L., and M. Eriksen. 2011. "Relational Leadership.” Human Relations 64 (11): 1425-1449.

Davis, S. 2013. "Dramatic Shape-Shifter and Innovative Teacher: The Creative Life and Legacy of Dorothy Heathcote." NJ Drama Australia Journal 37 (1): 25-40.

Deleuze, G., and F. L. Guattari. 1994. What is Philosophy? New York: Columbia University Press. 
Denis, J. L., A. Langley, and V. Sergi. 2012. "Leadership in the Plural." Academy of Management Annals 6 (1): 211-283.

Dibben, M., M. Wood, R. Macklin, and R. E. Riggio. 2017. "Rethinking Ethical Leadership Using Process Metaphysics." Chapter 9 in Radical Thoughts on Ethical Leadership, edited by Carole L. Jurkiewicz and Robert A. Giacalone, 169-198. Charlotte, NC: Information Age Publishing.

Fairhurst, G. T. 2004. "Textuality and Agency in Interaction Analysis." Organization 11: 335-353.

Fairhurst, G. T., and M. Uhl-Bien. 2012. "Organizational Discourse Analysis (ODA): Examining Leadership as a Relational Process." The Leadership Quarterly 23: 1043-1062.

Ferris, S. 2018. "Emotional Smith Breaks Down in Press Conference." Cricket Australia, March 29. https://www.cricket.com.au/news/steve-smith-press-conference-ball-tampering-scandal-speaksregret-bancroft-warner/2018-03-29.

Fotaki, M., K. Kenny, and S. J. Vachhani. 2017. "Thinking Critically About Affect in Organization Studies: Why it Matters." Organization 24 (1): 3-17.

Gherardi, S. 2017. "Which is the Place of Affect Within Practice-Based Studies.” M@n@Gement Unplugged 'Carte Blanche' 20 (2): 208-220.

Griffin, D. R. 2008. Unsnarling the World-Knot: Consciousness, Freedom, and the Mind-Body Problem. Berkeley, CA: University of California Press.

Heathcote, D. 1983. "Learning, Knowing, and Languaging in Drama: An Interview with Dorothy Heathcote." Language Arts 60 (6): 695-701. Language Across the Curriculum (September, 1983), National Council of Teachers of English.

Heifetz, R. A. 1994. Leadership Without Easy Answers. Cambridge, MA: Belknap/Harvard.

Hogg, M. A. 2001. "A Social Identity Theory of Leadership." Personality and Social Psychology Review 5 (3): 184-200.

Hooten, V. 2018. "Why Good People Do Bad Things, Good Weekend." Sydney Morning Herald, July 21. Fairfax Media, Australia.

Hope, S. 2016. "Bursting Paradigms: A Colour Wheel of Practice-Research." Cultural Trends 25: 74-86. Kitchen, J. 2011. "Grounding the Lyric Essay." Fourth Genre: Explorations in Nonfiction 13 (2): 115-121. Kotter, J. P. 1996. Leading Change. Boston, MA: Harvard Business School Press.

Ladkin, D. 2010. Rethinking Leadership: A New Look at Old Leadership Questions. Cheltenham, UK: Edward Elgar Publishing Inc .

Ladkin, D., and S. Taylor. 2010. "Leadership as Art: Variations on a Theme." Leadership 6 (3): 235-241.

Lather, P., and E. St Pierre. 2013. "Post-qualitative Research." International Journal of Qualitative Studies in Education 26 (6): 629-633.

Latour, B. 2004. "How to Talk About the Body? The Normative Dimension of Social Science Studies." Body and Society 10 (2-3): 205-229.

Lawrence, T. 2018. "Exclusive: The Case of the Missing Beach Judgment: NAB vs Lawrence." Independent Australia, August 10. Accessed October 23, 2019. https://independentaustralia.net/ business/business-display/exclusive-the-case-of-the-missing-beach-judgment-nab-vs-lawrence, 11775.

Lee, S.-J., A.-M. Lomdahl, L. Sawtell, S. Sculley, and S. Taylor. 2015. "Screenwriting and the Higher Degree by Research: Writing a Screenplay for a Creative Practice PhD." New Writing: The International Journal for the Practice and Theory of Creative Writing 13 (1): 85-97.

Lewin, K. 1951. "Problems of Research in Social Psychology." In Field Theory in Social Science, edited by D. Cartwright, 155-169. New York: Harper \& Brothers .

Manning, E. 2016. The Minor Gesture. Durham: Duke University Press.

Mintzberg, H. 2005. Managers Not MBAs: A Hard Look at the Soft Practice of Managing and Management Development. San Francisco, CA: Berrett-Koehler Publishers, Inc.

Morris, J. 2018. "I Gift Wrapped Commonwealth Bank for ASIC and it Did Nothing." Sydney Morning Herald. Fairfax Media, April 27. https://www.smh.com.au/business/banking-and-finance/i-giftwrapped-commonwealth-bank-for-asic-and-it-did-nothing-20180427-p4zbyk.html .

Parks, S.D. (2005). Leadership Can Be Taught. Boston, MA: Harvard Business School Press.

Probyn, E. 2010. "Writing Shame." In The Affect Theory Reader, edited by M. Gregg, and G. I. Seigworth, 71-90. London and Durham: Duke University Press. 


\section{[Type here]}

Pullen, A., C. Rhodes, and T. Thanem. 2017. "Affective Politics in Gendered Organizations: Affirmative Notes on Becoming-Woman." Organization 24 (1): 105-123.

Rhodes, C. 2018. "Sense-ational Organization Theory! Practices of Democratic Scriptology." Management Learning, Special Issue, Article, 1-14.

Sempert, M., L. Sawtell, P. Murray, S. Langley, and C. Batty. 2017. "Methodologically Speaking: Innovative Approaches to Knowledge and Text in Creative Writing Research." New Writing 14 (2): 205-222.

Shotter, J., and A. L. Cunliffe. 2002. "Managers as Practical Authors: Everyday Conversations for Action." In Management and Language: The Manager as Practical Author, edited by D. Holman, and R. Thorpe, 15-37. London: SAGE.

Springborg, C. 2010. "Leadership as Art - Leaders Coming to Their Senses." Leadership 6 (3): 243-258.

Stewart, K. 2007. Ordinary Affects. Durham, NC: Duke University Press.

Stroud, S. R. 2008. "Simulation, Subjective Knowledge, and the Cognitive Value of Literary Narrative." The Journal of Aesthetic Education 42 (3): 19-41.

Taylor, S. 2002. "Ties That Bind, Academy of Management Conference."

Taylor, S. 2008. "Theatrical Performance as Unfreezing, Ties That Bind at the Academy of Management." Journal of Management Enquiry 17 (4): 398-406.

Taylor, S. S. 2018. Staging Organization, Palgrave Studies in Business, Arts and Humanities. London: Palgrave Macmillan.

Taylor, S. S., and H. Hansen. 2005. "Finding Form: Looking at the Field of Organisational Aesthetics." Journal of Management Studies 42 (6): 1211-1231.

Uhl-Bien, M. 2006. "Relational Leadership Theory: Exploring the Social Processes of Leadership and Organizing." The Leadership Quarterly 17: 654-676.

Whitehead, A. N. [1929] 1978. Process and Reality [Corrected Edition]. New York, NY: Free Press.

Williams, P. 2013. "Creative Praxis as a Form of Academic Discourse." New Writing: The International Journal for the Practice and Theory of Creative Writing 10 (3): 250-260.

Wood, M. 2005. "The Fallacy of Misplaced Leadership." Journal of Management Studies 42: 1101-1121.

Wood, M., and M. Dibben. 2015. "Leadership as Relational Process." Process Studies 44 (1): 24-47.

Wood, M., P. Salovaara, and L. Marti. 2018. "Manifesto for Filmmaking as Organisational Research." Organization, 25 (6): 825-835. 